Bulletin d'Histoire Contemporaine de l'Espagne

$51 \mid 2017$

Les forces politiques durant la Seconde République espagnole

\title{
El insurreccionalismo anarquista durante la II República
}

L'insurrectionnalisme anarchiste pendant la Seconde République

The anarchistic insurrectionnisme during the Second Republic

\section{Ángel Herrerín López}

\section{OpenEdition}

\section{Journals}

Edición electrónica

URL: http://journals.openedition.org/bhce/694

DOI: $10.4000 /$ bhce.694

ISSN: 1968-3723

Editor

Presses Universitaires de Provence

Edición impresa

Fecha de publicación: 1 junio 2017

Paginación: 101-117

ISSN: 0987-4135

Referencia electrónica

Ángel Herrerín López, «El insurreccionalismo anarquista durante la II República », Bulletin d'Histoire Contemporaine de l'Espagne [En línea], 51 | 2017, Publicado el 09 octubre 2018, consultado el 21 diciembre 2020. URL : http://journals.openedition.org/bhce/694; DOI : https://doi.org/10.4000/bhce. 694 


\section{El insurreccionalismo anarquista durante la Segunda República}

\section{Ángel HERRERÍN LÓPEZ}

Universidad Nacional de Educación a Distancia

L a proclamación de la II República en España abrió un período de entusiasmo o, cuando menos, de esperanza entre diversos grupos políticos y clases sociales. La caída de la monarquía y la instauración de un régimen democrático suponían el inicio de un camino de reformas para los republicanos, mientras que para los socialistas era un paso intermedio hacia la instauración de una sociedad más justa e igualitaria. Sin embargo, para los anarquistas, la instauración de la República no representaba ningún cambio significativo y le asignaban los mismos defectos que a la monarquía derrocada. Su lucha estaba muy alejada de un simple cambio de régimen, su objetivo era la consecución de la auténtica revolución social.

Pero los anarquistas eran conscientes de las simpatías y esperanzas que despertaba la proclamación de la República en la clase trabajadora. Anarquistas y republicanos habían mantenido estrechas relaciones desde finales del siglo XIX. Dirigentes pertenecientes a grupos republicanos, como Farga Pellicer y González Morago, crearon los primeros grupos internacionalistas en nuestro país, aunque sufrieron una rápida transformación en sus planteamientos ideológicos hacia posiciones anarquistas. Una evolución que estuvo relacionada, por un lado, con la dinámica de las secciones de la Internacional y, principalmente, por los contactos con aquellos que representaban la posición más radical dentro de la organización: los bakuninistas; pero, por otro lado, y quizá más importante, por el desarrollo de los acontecimientos en España, que provocaron la desconfianza y facilitaron la crítica a la actividad política por parte de los anarquistas más radicales ${ }^{1}$. Baste señalar el devenir de la I República - con las reformas frustradas anunciadas por los federales, la conspiración de las clases poderosas contra la I República y la actividad política de los defensores del Antiguo régimen-, a lo que había que añadir el uso desmedido de la represión para sofocar el movimiento cantonalista en lugares como Sanlúcar de Barrameda o Alcoy, donde el protagonismo correspondió a los internacionalistas ${ }^{2}$. Actuaciones que reafirmaron a los anarquistas en su ideología, basada en la negación del Estado, el apoliticismo y la acción directa - entendida como oposición a cualquier tipo de representación, ya sea

1 Véase Anselmo Lorenzo, El proletariado militante. Memorias de un internacional, Madrid, Zero, 1974; Josep Termes, Anarquismo y sindicalismo en España (1864-1881), Barcelona, Crítica, 2000.

2 E1 gobierno republicano ordenó la represión a generales como Pavía o Martínez Campos, que causaron cientos de muertos. En Alcoy, dónde Martínez Campos sofocó la insurrección con un ejército de 6.000 soldados, hubo 16 fallecidos, más de una veintena de heridos, unos 400 detenidos y casi 300 personas fueron procesadas; C.A.M. Hennessy, La República Federal en España. Pi y Margall y el movimiento republicano Federal, 1868-1874, Madrid, Los libros de la catarata, 2010, p. 201-220, ; Clara LIDA, Anarquismo y revolución en la España del siglo XIX, Madrid, Siglo XXI, 1972, p. 212-227; Ana Guerrero et al., Historia politica, 1818-1874, Madrid, Istmo, 2004, p. 412-413. 
política, social o sindical- y facilitaron las críticas a cualquier régimen democrático ${ }^{3}$. A pesar de todo, anarquistas y republicanos siguieron compartiendo elementos importantes de sus culturas políticas, como el anticlericalismo, el federalismo, la enseñanza racionalista y el insurreccionalismo.

Los recelos de los anarquistas no impidieron que una inmensa mayoría de trabajadores mantuvieran sus esperanzas en la instauración de un régimen republicano. Situación que quedó patente el 14 de abril de 1931, cuando miles de personas ocuparon las calles de España para festejar su advenimiento. Entra ellas, un buen número de afiliados a la Confederación Nacional del Trabajo (CNT), de tendencia anarquista, que mantenían sus expectativas de mejorar las condiciones sociales y económicas en las que se desenvolvían sus vidas.

Sin embargo, los dirigentes anarquistas se alejaban del entusiasmo generalizado. $\mathrm{Su}$ discurso insistía en que el problema no era la forma, ya fuera república o monarquía, sino que la cuestión era el fondo: el sistema capitalista que los sustentaba. Así que a pesar de que eran conscientes de lo que la República representaba «en el alma de las multitudes», la CNT anunciaba que mantendría el ojo avizor, con el objetivo de iniciar «su gigantesca obra $\aleph^{5}$. Un objetivo que le llevó a protagonizar huelgas generales, levantamientos e insurreccionales.

El análisis de estas acciones, con especial atención a las realizadas en enero de 1932 y enero y diciembre de 1933, es el objetivo principal de este trabajo. Aunque, al mismo tiempo, habría que preguntarse, por un lado, por qué la CNT se lanzó a conseguir la revolución durante un régimen como el republicano, dónde las libertades eran mayores que en tiempos anteriores y permitían la lucha por los derechos de los trabajadores con más posibilidades de éxito. Por otro lado, el análisis de estos levantamientos nos tiene que ayudar a responder otra cuestión fundamental: hasta qué punto estos movimientos tuvieron la fuerza necesaria para acabar con la II República y conseguir la ansiada revolución social ${ }^{6}$.

\section{El contexto republicano}

Para contestar a la primera pregunta es necesario abordar, aunque sea de forma breve, dos asuntos que influyeron en la actuación anarquista: el enfrentamiento interno en el seno de la CNT por el control de la organización y la acción del gobierno republicano socialista en materia laboral y de orden público.

En la CNT siempre han existido dos grupos que han luchado por dirigir la organización. En tiempos de la II República los podemos denominar como anarcosindicalistas y anarquistas, que a su vez se encuadraban en la Federación Anarquista Ibérica (FAI). La lucha por el control de la organización implicaba, como es lógico, la realización de los planteamientos que defendía cada grupo. Los anarcosindicalistas entendieron la instauración de la

3 Ángel Herrerín, Anarquía, dinamita y revolución social. Violencia y represión en la España de entre siglos (1868-1909), Madrid, Los libros de la catarata, 2011, p. 36-39.

4 Solidaridad Obrera, 14 de mayo de 1931.

5 Solidaridad Obrera, 1 de mayo de 1931.

6 Varias obras han abordado la actuación de la CNT durante la II República y, en consecuencia, han tratado estas cuestiones, véase José Peirats, La CNT en la revolución española, tomo 1, Cary-Colombes, Ruedo Ibérico, 1971; Antonio Elorza, La utopia anarquista durante la guerra civil española, Madrid, Editorial Ayuso, 1973 (primera publicación en Revista de Trabajo, 1971, n 32); John Brademas, Anarcosindicalismo y revolución en España (1930-1937), Barcelona, Horas de España, 1973; Julián Casanova, De la calle al frente. El anarcosindicalismo en España (1931-1939), Madrid, Crítica, 1997. 
República como el espacio necesario para perfeccionar y ampliar la organización sindical, lo que permitiría, al mismo tiempo, la mejora de las condiciones de vida de la clase obrera. No renunciaban a alcanzar la sociedad libertaria, sino que aplazaban la revolución a largo plazo. Tiempo en el que fortalecerían el sindicato y alcanzarían reformas, lo que implicaba negociación, pero también la lucha a través de huelgas. Su labor se basaba en la educación y concienciación de la clase obrera, y su fuerza la obtenían del sindicato, de la organización de masas que representaban.

Esta tendencia tuvo su plasmación más visible en el documento firmado por treinta militantes que salió a la luz el $1^{\circ}$ de septiembre de 1931 en contra de la deriva que estaba tomando la Confederación por la acción de los «faístas». En el documento se señalaba que la revolución no podía ser obra y acción de una minoría audaz, sino que debía ser una acción constructiva de las masas. Los «treintistas», como fueron conocidos, defendían la actuación bajo el control de los sindicatos y, sin renunciar a la revolución, la posponían para cuando lo decidiera la CNT como consecuencia de una maduración y preparación adecuada?

Por su parte, los anarquistas pensaban en alcanzar la revolución de una manera inmediata. La República sólo representaba ese régimen de libertades en el que era más fácil desarrollar su actividad. Su organización era mucho más individualista y estaba basada en pequeños grupos con una fuerte cohesión ideológica. Si los anarcosindicalistas se basaban en la negociación y concienciación de los trabajadores, los anarquistas tenían en la acción de sus grupos la base de su prestigio y fuerza en la organización. Para la FAI había llegado la hora, era el momento de «declarar la huelga general revolucionaria en toda España y dar definitivamente la batalla a esos miserables» que detentaban el Poder ${ }^{8}$.

Había llegado el momento, por lo menos eso pensaba un grupo de anarquistas que había vivido los sucesos de mediados de abril desde la sorpresa y sentían haber dejado pasar una oportunidad histórica. Lo que había sucedido en España era, según su interpretación, una revolución a la que ellos no habían sabido dar la orientación adecuada. Así lo reflejaba un escrito del Comité Nacional de Defensa Confederal, que señalaba cómo partidos que no tenían suficiente crédito o simplemente no existían hacía pocos meses, según era el caso de Acción Republicana o el Partido Radical Socialista, se habían hecho los dueños de la situación. Una República, continuaba el comité, que «si en realidad [era] burguesa y no proletaria» se debía sola «y exclusivamente a la falta de preparación revolucionaria de la CNT o lo que es mejor, de sus militantes». Los anarquistas habían desaprovechado lo que denominaban el «momento psícológico de las revoluciones», es decir, ese instante de indecisión en el que se impone una idea, un programa o un grupo ante la vacilación del resto. Si la CNT no se hubiera visto sorprendida y hubiera estado al tanto de la «conspiración de los políticos» hubiera sabido impregnar el 14 de abril con un sentido revolucionario y no burgués. La enseñanza que sacaban los anarquistas era clara: los militantes de la CNT se tenían que haber echado a la calle, ocupado los edificios municipales e incitado al pueblo a la revolución, deberían haber penetrado «tumultuosamente en los cuarteles abrazando a los soldados (desarmándolos), dando gritos de ¡Viva los hijos del Pueblo!, y órdenes

7 Los firmantes del documento fueron: Juan López, Juan Peiró, Agustín Gibanel, Ricardo Fornells, Ángel Pestaña, José Girona, Daniel Navarro, Jesús Rodríguez, Antonio Valladriga, Miguel Portoles, Joaquín Roura, Joaquín Lorente, Progreso Alfarache, Antonio Peñarroya, Camilo Piñón, Joaquín Cortés, Isidoro Gabín, Pedro Massoni, Francisco Arín, José Cristiá, Juan Dinarés, Roldán Cortada, Sebastián Clará, Ramón Viñas, Federico Uleda, Pedro Cané, Mariano Prat, Espartaco Puig, Narciso Marcó, Jenaro Minguet; José Peirats, op. cit., p. 59-63.

8 Tierra y Libertad, 15 de agosto de 1931; en John Brademas, op. cit., p. 74. 
confederales de desmilitarización y disolución del ejército nacional», si se hubiera hecho esto, se hubiera iniciado «la liberación social»?.

Pero no todo estaba perdido, los anarquistas pensaban que la situación se podía reconducir y hacerla propicia para mantener el impulso de la revolución. El convencimiento de estar viviendo un momento revolucionario en la historia de España, explica el cambio de rumbo que la CNT puso en marcha en este período. Si en tiempos pretéritos sus luchas eran, primordialmente, sindicales; con el derrocamiento de la monarquía y advenimiento de la República, las acciones tuvieron pretensiones nacionales con el objetivo de la revolución social. Se despreciaba, igualmente, la actividad individual basada en el atentado para «evitar crear la epidemia terrorista que actúa sobre el cuerpo social como elemento estrangulador de la revolución». Para los anarquistas no era el tiempo del individualismo valiente, sino de la insurrección popular. El momento, claramente revolucionario, requería dejar de prestar «atención a pequeñeces», y como tales se entendían las luchas por las mejoras en las condiciones de vida de los trabajadores, por lo tanto, era necesario:

que no se planteara ninguna clase de conflicto de orden económico, moral o personal que no tuvieran una estrecha relación con las necesidades revolucionarias del momento, pues resulta paradójico que mientras se vive al afán de la Revolución Social, se planteen huelgas o conflictos para obtener mejoras materiales, $y$, acaso también, para vengar ciertas injusticias de carácter personal que ninguna de ellas quedaría sin venganza o sanción en una revolución triunfante ${ }^{10}$.

Pero los anarquistas necesitaban el control de la organización para avanzar por el camino de la revolución. La ofensiva «faísta» comenzó en el mismo verano de 1931 y tuvo su primer resultado en la destitución de Juan Peiró -figura señalada del anarcosindicalismo-, al frente de la redacción de Solidaridad Obrera, en septiembre del mismo año. Su puesto sería ocupado por el «faísta» Felipe Alaiz al mes siguiente. La ofensiva estuvo marcada por una huelga general en la metalurgia, un levantamiento en la cárcel Modelo de Barcelona y la consiguiente represión a cargo del Gobernador civil, Anguera de Sojo. Circunstancias que dificultaban la actuación moderada de los anarcosindicalistas con respecto a la República ${ }^{11}$. De todas formas, todavía a finales de año, el secretariado general de la CNT estaba en manos de un destacado treintista como Ángel Pestaña, mientras que una regional tan emblemática como la catalana, lo estaba en las del moderado Emilio Mira. Situación que se mantuvo poco tiempo, pues la crítica por la actuación de ambos durante el levantamiento de enero de 1932, y, principalmente, su respuesta a la represión ejercida desde el Estado, implicó su sustitución por dirigentes de la FAI en los meses siguientes.

Lo cierto es que la actuación del gobierno republicano-socialista iba a dar argumentos a los «faístas» en su lucha contra los moderados en la CNT. En primer lugar, por la política que el dirigente de la Unión General de Trabajadores (UGT), Francisco Largo Caballero, puso en marcha al frente del Ministerio de Trabajo. El enfrentamiento de la CNT con la UGT tenía que ver con su disputa por el control del movimiento obrero. Un enfrentamiento que venía de lejos y que había tenido su representación más cercana durante la Dictadura de Primo de Rivera. Los socialistas no promovieron ningún tipo de actuación contra el golpe del general, y pasaron de la neutralidad a la colaboración con la Dictadura. Largo

9 Instituto Internacional de Historia Social de Amsterdam (en adelante IIHS), sig. CNT, 93 B. Informe del Comité Nacional de Defensa Confederal. Orientaciones Revolucionarias.

10 IIHS, sig. CNT, 93 B. Organización de Defensa Confederal. Comité Nacional. Orientaciones Revolucionarias.

11 Antonio Elorza, op. cit., p. 449. 
Caballero participó como vocal en el Consejo de Trabajo y también en el Consejo de Estado, órgano consultivo de ayuda al Directorio Militar. La UGT colaboró también en la organización corporativa creada por el Ministerio de Trabajo. El modelo se basaba en el sistema fascista italiano, aunque con ciertas diferencias. La base de la nueva organización era los «comités paritarios», donde obreros y empresarios discutían sus diferencias. Los ugetistas pusieron como condición para su participación ser la única central presente en dichos comités. Con esta actuación, no sólo evitaban su posible ilegalización, sino que consolidaron su organización y aumentaron el número de afiliados. Por el contrario, la CNT se vio abocada a la clandestinidad, con la consiguiente represión y el desmantelamiento de sus estructuras ${ }^{12}$.

Los «cenetistas» no olvidaban esta reciente historia de colaboración socialista con la Dictadura y mostraban sus recelos hacia la persona de Largo Caballero. La puesta en marcha de los Jurados Mixtos, versión republicana de los comités paritarios, implicó el enfrentamiento con la central socialista y con el gobierno de la República. La implantación de los Jurados Mixtos fue entendida, además de como una actitud ventajista que favorecía a la UGT, como «una flecha apuntando al corazón de la CNT y a sus tácticas de acción directa $\gg^{13}$. La CNT no estaba dispuesta a aceptar una ley que eliminaba una de sus señas de identidad más significativa, en la que había basado su actividad sindical en el pasado. La oposición a aceptar la nueva norma supuso la ausencia de la organización anarcosindicalista en muchas de las negociaciones laborales, lo que implicó la omnipresencia de la UGT en dichas negociaciones y el consiguiente incremento de afiliados. No hay que olvidar que la República se desenvolvió en tiempos de crisis económica y que los sindicatos eran centros de contratación, lo que implicaba el enfrentamiento entre ambas centrales por el control del trabajo. Estas circunstancias se reflejaron, de una manera especial, en el medio rural, donde la Federación Nacional de Trabajadores de la Tierra (FNTT), sección integrada en la UGT, pasó de contar con 35.000 afiliados en junio de 1930 a más de 390.000 en junio de $1932^{14}$. La CNT, por su parte, convocaba un buen número de huelgas, con duros enfrentamientos, que dejaban varios muertos en las calles de España. El movimiento obrero estaba dividido, al tiempo que el paro aumentaba sin que las huelgas o la nueva legislación laboral consiguieran mejorar las condiciones de vida de los trabajadores ${ }^{15}$.

El gobierno republicano se encontró con el importante problema del incumplimiento de la legislación laboral por parte de empresarios y latifundistas. La UGT utilizó, sobre todo, la negociación a través de los Jurados Mixtos para conseguir el acuerdo entre trabajadores y patronal, y evitar, de este modo, las huelgas. Pero los empresarios no respetaban los acuerdos alcanzados si no eran de su agrado. Los «ugetistas» veían como la posición ultramontana de una patronal anclada en el pasado de la arbitrariedad, daba al traste con sus intentos de reforma. Frustración que ya quedó reflejada en el XVII congreso de la UGT celebrado en los meses finales de 1932, y que fue en aumento según se acercaba el fin de la legislatura ${ }^{16}$.

Todas estas cuestiones eran utilizadas por los anarquistas, en su política de desprestigio del régimen republicano, para señalar, invariablemente, la imposibilidad de un cambio real si no era mediante la revolución social. Argumentos que tomaban mayor consistencia

12 Santos Juliá, Los socialistas en la política española, 1879-1982, Madrid, Taurus, 1997, p. 126-131.

13 José Peirats, op. cit., p. 52.

14 Juan Avilés y otros, Historia politica, 1875-1939, Madrid, Istmo, 2002, p. 343.

15 John Brademas, op. cit., p. 72-75.

16 Marta Bizcarrondo, Historia de la UGT. Entre la democracia y la revolución, 1931-1936, Madrid, Siglo XXI, 2008, p. 69-83. 
cuando se oía al Presidente del Gobierno, Manuel Azaña, decir en las Cortes, el 21 enero de 1932 , que

nada tenemos que ver aquí,..., con los conflictos específicos del trabajo. No. Había unas bases entre patronos y obreros. Yo no sé ni me interesa para este momento que se cumplan o se dejen de cumplir. Unas bases de trabajo pactadas jamás dan derecho a nadie para ocupar fábricas, para asaltar Ayuntamientos, para apoderarse de centrales telefónicas y agredir a la fuerza pública. Para eso no hay motivo nunca ${ }^{17}$.

Palabras que tomaban un significado excepcional para una clase obrera que había esperado mucho tiempo la llegada de un régimen republicano que, supuestamente, traería la justicia social. Sin embargo, veía como la represión se ejercía de forma especial contra ellos a pesar de que, como he señalado, los patronos eran los primeros en tener una actitud de rebeldía contra el nuevo régimen, al no aceptar los acuerdos que se alcanzaban dentro de la legislación laboral republicana. De hecho, se puede hablar de una «ofensiva patronal», en palabras de Marta Bizcarrondo, con una clase empresarial que no aplicaba la legislación social. Cuestión que era fundamental en las relaciones laborales, pues el mayor número de huelgas no se producía por una reivindicación concreta, como podía ser un aumento salarial, sino por el incumplimiento de la legislación social ${ }^{18}$.

La situación era aún más delicada en el campo que en la ciudad. Los campesinos llevaban una existencia mísera que el Gobierno Provisional había intentado paliar con urgencia mediante decretos que también sufrieron la oposición de los grandes terratenientes. Pero, además, la actuación de las fuerzas del orden público era mucho más complicada en el medio rural. Estas fuerzas estaban «más cercanas» al poder de los grandes propietarios que al del Ministro de Gobernación en Madrid. No resultaba nada excepcional que el propietario de unas tierras solicitara la presencia de la Guardia civil, a la que daba alojamiento en sus tierras y pagaba los gastos de manutención y hospedaje, cuando se iban a realizar labores de recolección o ante la posibilidad de una manifestación o huelga ${ }^{19}$. El propio dirigente ugetista Enrique de Santiago señalaba que la lucha era más difícil «en los pueblos y en las aldeas, donde el cacique, en buenas migas con el sargento de la Guardia civil, es amo y señor de la libertad y de la vida de los ciudadanos $\rangle^{20}$. En este contexto, los dirigentes republicanos y socialistas tuvieron que enfrentarse a situaciones de difícil explicación, como los hechos acaecidos en localidades como Arnedo o Casas Viejas. Represión que los «faístas» utilizaron ya no sólo contra la República, con el objeto de convencer a los trabajadores de la imposibilidad de mejora con el nuevo régimen, sino también contra sus compañeros más moderados para lograr el control de la CNT. Un control que no sólo se ejerció desde la dirección del sindicato, sino también a través del dominio en organizaciones supuestamente supeditadas a la CNT, como eran los comités de defensa y los comités pro-presos.

Las reivindicaciones laborales que, mediante importantes huelgas, comenzaron en mayo de 1931, junto a las ocupaciones de fincas, de septiembre y octubre, dieron paso a levantamientos revolucionarios al año siguiente.

17 Manuel Azaña, Discursos parlamentarios, Madrid, Publicaciones del Congreso de los Diputados, 1992, p. 133.

18 Marta BizCARRONDO, op. cit., p. 76-80.

19 Julián Casanova, op. cit., p. 37.

20 Boletín de la UGT, $\mathrm{n}^{\circ}$ 35, noviembre de 1931; en Marta Bizcarrondo, op. cit., p. 72. 


\section{El levantamiento de enero de 1932}

Aunque la historiografía siempre ha considerado que la CNT protagonizó tres movimientos insurreccionales, en enero de 1932 y en enero y diciembre de 1933 , lo cierto es que el análisis del primero de ellos niega la organización o dirección de este movimiento al sindicato confederal, como veremos a continuación.

El 18 de enero de 1932, los mineros del Alto Llobregat y Cardoner declararon una huelga que derivó en levantamiento insurreccional. Enero estaba siendo un mes con importantes movilizaciones obreras y campesinas que sufrieron la respuesta de una represión brutal. Más de una decena de trabajadores habían caído por la acción de las fuerzas del orden en lugares como Castilblanco, Salamanca, Jeresa, Epila, Arnedo, etc., al tiempo que se convocaban huelgas en buena parte de España. En el Alto Llobregat, todo comenzó en Figols y se extendió por otras localidades de la zona. Los motivos que llevaron a los mineros a la insurrección estaban relacionados con los derechos de reunión y asociación que, a pesar de la legislación republicana, les eran negados, a lo que había que añadir las duras condiciones de trabajo existentes en las minas, la falta de seguridad y la negativa de los patronos a respetar los acuerdos alcanzados ${ }^{21}$. La insurrección no tuvo preparación alguna. Lo que comenzó como una huelga para conseguir mejoras concretas, derivó, por acción de los más radicales, en un intento revolucionario. De hecho, el Comité Regional de Cataluña de la CNT no tenía conocimiento de lo que se avecinaba en Figols. Su secretario general, Emilio Mira, al enterarse del levantamiento, se desplazó de forma urgente a la zona, donde le informaron que estaban «en armas» con el objetivo de hacer la revolución. Mira, que había pertenecido a la FAI, formaba parte ahora de la fracción moderada de la organización, por lo que, para evitar que su informe pudiera interpretarse como tendencioso, decidió hacerse acompañar por la persona que estaba al frente del movimiento, un tal Prieto. Éste presentó un manifiesto, ante la organización reunida en Barcelona, en el que se decía que «Figols se había insurreccionado creyendo que iba a implantarse una dictadura en España ${ }^{22}$. Planteamiento que, seguramente, tenía su origen en las noticias que llegaban sobre la cruenta represión que tenía lugar en distintos lugares del territorio nacional.

En una reunión celebrada en la Ciudad Condal, el viernes 22, tres comarcales solicitaron libertad de acción para sumarse al movimiento, pero, aunque fue concedida, no se incorporaron al levantamiento. Algo parecido sucedió entre los sindicatos barceloneses. Según Mira, los militantes, reunidos en la noche del 23, estaban indecisos, aunque en último término decidieron proclamar la huelga revolucionaria. La decisión era importante porque la interpretación que se hacía del momento era que Cataluña miraba hacia Barcelona y España hacia Cataluña. Sin embargo, para Mira el problema era que «faltaba entusiasmo o no estaba la organización en condiciones» para un intento de ese nivel. Además, el Secretario catalán señalaba otra cuestión bastante más mundana: el día acordado para la proclamación de la huelga era sábado, día de cobro, lo que, según parece, disminuía las apetencias revolucionarias. A pesar de los análisis poco halagüeños para el éxito del movimiento, los sindicatos barceloneses, con el apoyo explícito de los Comités local, regional y nacional de la CNT, decidieron continuar con la acción, ante la posibilidad de que en esos momentos

21 Cristina Borderías y Mercedes VILANOVA, "Cronología de una insurrección: Figols en 1932», Estudios de Historia Social, Madrid, Ministerio de trabajo, n² 24-25, 1983, p. 187-199.

22 IIHS, sig. CNT, 93 B. Acta de la Federación Local de Barcelona de finales de enero de 1932 para analizar la insurrección de este mes. Copia firmada por el secretario de esta Federación el 3 de marzo de 1932. 
hubiera compañeros que estuvieran «batiéndose en las calles de Barcelona», ya que las seis era «la hora señalada para que ocurran hechos de gran violencia». El domingo por la tarde, todos los comités reunidos reconocieron que estos hechos no se habían producido y el Comité nacional acordó retirar la orden de huelga que había dado para toda España ${ }^{23}$.

Mientras esto sucedía en Barcelona, en Figols y localidades de la zona como Cardona, Berga, Sallent y Suria se cerraban comercios y se tomaban ayuntamientos proclamando el comunismo libertario. En un total de diez municipios llegó a ondear la bandera roja y negra $^{24}$. El Gobierno envió al Ejército que redujo a los revolucionarios y restableció el orden. La represión incluyó la detención de decenas de militantes detenidos, mineros que fueron despedidos de sus trabajos, los cierres de locales de la CNT y la prohibición de su prensa.

Había pasado «el primer intento serio de revolución social en España» ${ }^{25}$, según defendía Federica Montseny. Llegaban las consecuencias y, entre ellas, la búsqueda de responsabilidades ante el fracaso del movimiento, cuestión que no puede separarse de la lucha por el control de la CNT. Jover, del sindicato de la madera en Barcelona y miembro del Comité nacional, denunciaba la actitud que tanto el Comité regional catalán como el propio nacional habían tenido en la marcha de los acontecimientos, con mención especial de sus dirigentes, Emilio Mira y Ángel Pestaña. Para Jover, el triunfo o fracaso del movimiento había dependido de algo tan sencillo como era el lanzamiento de un manifiesto para toda España en el que se llamara a secundar el levantamiento. El manifiesto no vio la luz, como tampoco se llegó a constituir un comité ejecutivo que dirigiese la sublevación, por lo que afirmaba que «consciente o inconscientemente se ha traicionado al movimiento» ${ }^{26}$.

La situación se complicó en mayor medida con la detención de más de un centenar de «cenetistas» que fueron embarcados en el vapor Buenos Aires para su deportación a causa de la reciente insurrección. Entre los detenidos figuraban militantes tan conocidos como Buenaventura Durruti o los hermanos Francisco y Domingo Ascaso. El barco partió a principios de febrero de 1932 con destino a los dominios españoles en África. El secretario general del Comité nacional, Ángel Pestaña, realizó gestiones de clemencia para los deportados ante el propio Azaña, quien planteó acortar el confinamiento de los desterrados a cambio de una «paz duradera» ${ }^{27}$. Además, Pestaña transformó la propuesta de la Regional de Aragón, Rioja y Navarra de declarar una huelga general, en respuesta a las deportaciones, en una simple jornada de protesta cuando contactó con el resto de regionales; lo que recrudeció los ataques de elementos anarquistas contra los dirigentes moderados de la organización ${ }^{28}$.

Lo cierto era que lo sucedido en el Alto Llobregat en enero de 1932 no fue ningún movimiento insurreccional promovido por la organización confederal; no contó con ningún tipo de planificación ni convocatoria a nivel nacional, ni siquiera con una comunicación

23 IIHS, sig. CNT, 93 B. Acta de la Federación Local de Barcelona de finales de enero de 1932 para analizar la insurrección de este mes. Copia firmada por el secretario de esta Federación el 3 de marzo de 1932.

24 Federica Montseny, «Pueblos mineros y pueblos heroicos de España», El Luchador, 12 de febrero de 1931; en John Brademas, op. cit., p. 87.

25 Federica Montseny, "Ante un momento grave de la historia de España», El Luchador, 29 de enero de 1931; en John Brademas, op. cit., p. 87.

26 IIHS, sig. CNT, 93 B. Acta de la Federación Local de Barcelona de finales de enero de 1932 para analizar la insurrección de este mes. Copia firmada por el secretario de esta Federación el 3 de marzo de 1932.

27 Manuel Ażã̃a, Memorias politicas y de guerra, I, Barcelona, Crítica, 1981, p. 417.

28 Antonio Elorza, op. cit., p. 452-453. 
de la comarcal a la regional catalana que informara sobre la preparación de una acción revolucionaria; fue una huelga a nivel comarcal que derivó en levantamiento en algunos pueblos de la zona. Levantamiento que no supuso ninguna mejora en la situación de los trabajadores, como tampoco reportó nada positivo para la CNT, por mucho que desde las filas anarquistas se pusiera el acento en el heroísmo de los revolucionarios y en los momentos de libertad que habían vivido los pueblos en los que había hondeado la bandera confederal. Así que los anarquistas insistían en la denuncia de la represión sufrida por los militantes confederales, con especial referencia a los deportados. Sin embargo, la organización confederal no abrió, tras la insurrección, ningún debate serio que analizara lo que había pasado en el Alto Llobregat, que delimitara las responsabilidades de cada parte en los sucesos, que buscara los errores cometidos para que futuros movimientos, de producirse, no supusieran una debacle ni para los trabajadores ni para la CNT. Las reacciones anarquistas se dirigieron más hacía la descalificación furibunda de los responsables confederales, que al análisis de los hechos y la búsqueda de soluciones.

$\mathrm{Al}$ frente de esta campaña se situaba Federica Montseny, que en un artículo titulado «Yo acuso»-copia del título del artículo en que Emilio Zola denunció la injusticia del caso Dreyfus-, culpaba a los «treintistas» como responsables del fracaso de la revolución y, en consecuencia, de las deportaciones. Federica señalaba que cuando en toda España se esperaba sólo una indicación para lanzarse al levantamiento, en referencia al manifiesto que no llegó a salir, cuando la CNT veía la «posibilidad de realizar su ideario, traicionaron una vez más al movimiento». Aunque su crítica más incendiaria se dirigió hacia los responsables de la organización: Emilio Mira y Ángel Pestaña. Sobre el primero, se preguntaba: «qué enchufe, qué sinecura, qué ventajoso empleo le han prometido...» por evitar que el levantamiento se extendiera a toda Cataluña, para contestarse que «esto bien vale al menos un sueldo mensual de quinientas pesetas...». Sobre el segundo, «qué diputación, ministerio o gobierno civil le han prometido...» por haber saboteado el movimiento por retrasar la huelga y conseguir que «la gente, desorientada, indecisa, se reintegrara al trabajo», para terminar diciendo: « $i \mathrm{Oh}$, esto bien vale más de mil pesetas mensuales» ${ }^{29}$.

Acusaciones sin base, pero que tuvieron unos resultados inmediatos: Pestaña dejaba la secretaría general de la CNT en marzo de 1932; un mes después, Mira salía de la dirección de la regional catalana. Ambos fueron sustituidos, en sus respectivos cargos, por los «faístas» Manuel Rivas y Alejandro Gilabert. En los meses finales de ese año, los dirigentes de la FAI habían conseguido el control de la organización tras la expulsión de un buen número de anarcosindicalistas, entre otros, Juan López, Agustín Gibanel o el propio Ángel Pestaña, y hasta de federaciones locales enteras, como fue el caso de la de Sabadell ${ }^{30}$.

Por su parte, anarcosindicalistas, como Juan Peiró, señalaban el fracaso que había supuesto el movimiento de Figols, al tiempo que recordaban las advertencias que desde el famoso manifiesto de los treinta se hacía a la actuación irresponsable de los cabecillas de la FAI. Además, hacía una reflexión importante sobre la conveniencia de ajustar futuros movimientos a la realidad que suponía el fuerte poder defensivo del Estado ${ }^{31}$ que iba a quedar demostrado en las insurrecciones siguientes.

29 Federica Montseny, «Yo acuso», El Luchador, 19 de febrero de 1932; en John Brademas, op. cit., p. 90.

30 Antonio Elorza, op. cit., p. 454.

31 Juan Peíró, «Después de los sucesos», Cultura Libertaria, en Antonio Elorza, op. cit., p. 452. 


\section{La insurrección de enero de 1933}

El inicio de la insurrección de enero de 1933 se encuentra, al igual que en el movimiento anterior, en el intento de hacer derivar una huelga en un hecho revolucionario. Aunque, ahora sí, era la organización en pleno quien intentaba planificar esta iniciativa. El origen estuvo en las reivindicaciones que los ferroviarios hicieron llegar al Gobierno, y que el socialista Indalecio Prieto se había negado a aceptar. Los ferroviarios cenetistas, adscritos a la Federación Nacional de la Industria Ferroviaria (FNIF), se dirigieron a la CNT para conseguir el apoyo en sus pretensiones y en la supuesta huelga que iban a realizar. En un Pleno de Regionales celebrado en Madrid a principios de diciembre de 1932, la mayoría de representantes de los comités regionales señalaban los síntomas inequívocos que presentaba el país para promover una sublevación. Regionales, como la de Cataluña, no dudaban en mostrar su apoyo al movimiento ferroviario para darle una «mayor vitalidad», en fin, para transformanlo en un hecho revolucionario. En la estrategia no faltaba la segura represión del Estado, que valdría para impulsar la sublevación. Los ferroviarios cenetistas entendían que la huelga derivaría «a un hecho de fuerza aún en contra de la voluntad de los trabajadores, por la acción represora del Gobierno», a lo que irremisiblemente serían empujados «para no ser aplastados» $»^{32}$.

A pesar de que la mayoría de los representantes regionales defendían que la situación general en España era «francamente revolucionaria», la realidad indicaba que esta apreciación se sustentaba más en las ansias d'un grupo qu'en el análisis de la realidad. Por un lado, porque la huelga que tenía que dar paso al levantamiento estaba lejos de convocarse. La mayoría de los ferroviarios estaban afiliados a la Sociedad Nacional Ferroviaria, perteneciente a la UGT, que apostaba más por la negociación que por la huelga. Pero es que, por otro lado, la situación no estaba clara dentro de la propia Federación ferroviaria cenetista. De hecho, en una votación entre sus subsecciones, treinta y seis declararon no estar preparadas para la huelga, mientras que treinta y cinco lo hicieron en sentido afirmativo. Además de esta importante división, el Gobierno concedió alguna de las peticiones, por lo que la huelga no llegó a producirse. La propia Federación cenetista tuvo que desistir porque, como era evidente, no «contaba con la adhesión de todos los ferroviarios» ${ }^{33}$.

Estas nuevas circunstancias no influyeron en el ánimo de los «faístas», que continuaron con sus pretensiones de lanzarse a la revolución, indiferentes a la nueva situacióny al acuerdo confederal que señalaba la huelga ferroviaria como paso previo para el levantamiento. Más bien al contrario, adelantaron los preparativos tras la explosión de uno de sus arsenales, y convocaron a la revolución con fecha y hora determinada: el día 8 de enero a las 8 de la tarde ${ }^{34}$. Esperaban que, una vez en la calle, su espíritu revolucionario contagiara ya no sólo al resto de la organización, sino también al pueblo en general. La convocatoria contó, además, con una ambigüedad que hace dudar de los medios utilizados para conseguir su objetivo. La llamada al movimiento partió del Comité de Defensa catalán, que intuyó la futura actuación policial contra la organización, «estudió la situación de represión que se estaba gestando y procedió a intensificar aceleradamente la preparación de efectivos», sin

32 IIHS, sig. CNT, 93 B. Actas del Pleno de Regionales de la CNT, celebrado en Madrid, el 2 de diciembre de 1932 y actas del Pleno de locales y comarcales del Comité Regional del Trabajo de Cataluña del 10 de diciembre de 1932 .

33 IIHS, sig. CNT, 93 B. Extracto de las actas del Pleno Nacional de Regionales celebrado en Madrid, el 30 de enero de 1933.

34 John Brademas, op. cit., p. 101. 
esperar a que estallara la huelga, con la esperanza que el movimiento sería secundado por el resto de la organización ${ }^{35}$. El Comité de Defensa catalán contó con el apoyo del secretario del Comité Nacional de los propios Comités de Defensa, Manuel Rivas, quien, a su vez, era secretario general del Comité Nacional de la CNT. Así que cuando Rivas firmó el documento que llamaba a la movilización como secretario de defensa, buena parte de la organización creyó que quien convocaba el movimiento era la organización sindical, y no dichos comités, que, por otro lado, estaban en manos «faístas» y no tenían potestad para tomar una decisión de esas características ${ }^{36}$.

En consecuencia, la CNT se desvinculaba del levantamiento, mientras la FAI lo hacía suyo. De hecho, el Pleno de Locales y Comarcales de Cataluña, de finales de enero, eximió de responsabilidades al Comité Regional de la CNT en Cataluña en el levantamiento, al considerar que el movimiento fue declarado al margen de la organización. En el mismo sentido, el Comité Nacional de la CNT señaló que la lucha quedó desautorizada desde el momento en que la Federación ferroviaria desconvocó la huelga. Toda esta situación, abrió la crítica a la actuación de los comités de defensa y a un debate que intentó limitar, de una vez por todas, sus atribuciones. El Pleno Nacional de Regionales, celebrado en junio de 1933, acordó la incompatibilidad entre las secretarías generales de la CNT y del Comité de Defensa; acuerdo que se extendió a los secretariados de las comarcales, locales y regionales. Al mismo tiempo, recordaba que los comités de defensa debían centrar su actuación, exclusivamente, en la preparación de los movimientos revolucionarios, nunca en su ejecución, papel que quedaba en manos de la organización sindical ${ }^{37}$.

La insurrección tuvo especial seguimiento en Cataluña, Levante y Andalucía. Al igual que había sucedido un año antes, los anarquistas izaron la bandera roja y negra de la Confederación en algunos pueblos y proclamaron el comunismo libertario. La dinámica que la revolución tuvo en estas localidades retrotraía a modos de actuación del último cuarto del siglo anterior, que deberían estar superados. Los revolucionarios se dirigían al cuartel de la Guardia civil para conminar a los agentes a unirse a la rebelión, a continuación se apoderaban del ayuntamiento y del archivo de la propiedad, para la destrucción «en auto de fe» de los títulos; posteriormente se atrincheraban en el pueblo y no trataban de extender la lucha más allá de su demarcación -seguramente ante la creencia de que la misma acción estaba teniendo lugar en el resto de localidades de la zona-, así que esperaban a la comunicación del triunfo de la revolución o a que las fuerzas del orden llegaran ${ }^{38}$.

Estos levantamientos estaban relacionados, en muchos casos, con la situación de miseria en la que se desenvolvía la vida de los campesinos españoles. A este respecto, habría que preguntarse hasta qué punto la proclamación del comunismo libertario significaba para los lugareños algo más que un reparto de tierras, que consideraban necesario para su supervivencia. El gobierno republicano-socialista había aprobado una serie de decretos, como el de laboreo forzoso y el de términos municipales, que pretendían mejorar la situación del campesinado, pero cuyo desarrollo fue controvertido y lento. Igual sucedió con la legislación más importante con la que se pretendía solucionar los problemas del

35 IIHS, sig. CNT, 93 B. Extracto de las actas del Pleno Nacional de Regionales celebrado en Madrid, el 30 de enero de 1933.

36 John Brademas, op. cit., p. 101-103; Antonio Elorza, op. cit., p. 455-456.

37 IIHS, sig. CNT, 93 B. Extracto de las actas del Pleno Nacional de Regionales celebrado en Madrid, el 12 de junio de 1933.

38 Vease Ángel Herrerín, op. cit., p. 208-214; los acuerdos de las conferencias comarcales de julio y agosto de 1876, en Josep TERMES, op. cit., p. 267. 
campo, como fue la ley de Reforma Agraria, que se aprobó en agosto de 1932; es decir, tras un año y cuatro meses de la instauración de la República y gracias al impulso que para las fuerzas en el Gobierno supuso el fracaso de la rebelión protagonizada por el general Sanjurjo. Pero es que, además de la lentitud, la legislación vigente chocó con la intransigencia de los terratenientes, que incumplian sistemáticamente ya no sólo decretos y leyes republicanas, sino los acuerdos alcanzados con los trabajadores en el marco de los Jurados Mixtos. Son muchos los latifundistas que dejaban de cultivar sus tierras, y miles los labriegos que no ganaban jornal alguno; a los que los primeros decían: «¿No queríais República? ¡Pues comed República!» ${ }^{39}$.

Esta situación se agravaba con la actuación de las fuerzas del orden en el campo, que provocó actos de represión de difícil justificación. El caso más conocido es lo sucedido en Casas Viejas, el 11 y 12 enero de 1933. Lejos de pretender realizar un análisis pormenorizado de los hechos, es importante señalar que con anterioridad a la insurrección libertaria estaba planteada una huelga campesina en las provincias de Cádiz y Sevilla, como protesta por el paro forzoso en el que se encontraban miles de jornaleros desde que acabó la siega, con los consiguientes problemas de hambre. Los jornaleros recibían como subsidio de paro, lo que se denominaba el bono - que los campesinos llamaban «la limosna»-, consistente en el pago de 1 peseta a los solteros y 1,50 a los casados; cuando el kilo de pan costaba 95 céntimos ${ }^{40}$.

Con este ambiente de fondo, los campesinos de Casas Viejas se unieron a la insurrección anarquista y ocuparon la localidad. La llegada de las fuerzas del orden, al mando del capitán Rojas, significó la puesta en marcha de una represión que supuso el incendio de una casa, con ocho miembros de la familia de uno de los anarquistas -Seisdedos- en su interior, de los que murieron seis, el fusilamiento de otros catorce campesinos, y la detención de varias decenas, con las correspondientes denuncias de tortura ${ }^{41}$.

La República tenía un grave problema con la actuación de las fuerzas del orden en el campo español, ya que cualquier actuación, hasta aquellas que eran pacíficas, eran tomadas como un acto de agresión o, cuando menos, de ruptura del orden. Es evidente que el gobierno de la República tenía derecho a reprimir cualquier levantamiento que se produjera contra el orden público, pero no es menos cierto que también estaba obligado tanto a hacer cumplir la legalidad, como a controlar que la actuación de las fuerzas del orden estuviera de acuerdo a la ley. Pues bien, en ambos asuntos, la actuación del Gobierno favoreció los intereses de los poderosos en detrimento de los más débiles; no obligó a los primeros a cumplir las leyes y acuerdos firmados dentro de la legalidad, ni sancionó la actuación desmedida de las fuerzas del orden contra los segundos; más bien al contrario, los miembros del Gobierno se apresuraban a justificar su actuación. Así, por ejemplo, Azaña señalaba en las Cortes, el 2 de febrero, que «en Casas Viejas no ha ocurrido, sino lo que tenía que ocurrir». Palabras que fueron acogidas con «fuertes rumores y protestas en los bancos de las minorías; contraprotestas en la mayoría»; para continuar diciendo: «planteado un conflicto de rebeldía a mano armada contra la sociedad y contra el Estado, lo que ha ocurrido en Casas Viejas era absolutamente inevitable ${ }^{42}$. Azaña defendía la actuación de las fuerzas del orden antes de conocer la realidad de lo ocurrido en Casas

39 Eduardo de Guzmán, La tragedia de Casas Viejas, 1933, Madrid, Vosa, 2007, p. 27

40 Ramón J. Sender, Casas Viejas, Zaragoza, Larumbe, 2004, p. 19; Eduardo de Guzmán, op. cit., p. 19-20 y 27.

41 Ramón J. Sender, op. cit; Eduardo de Guzmán, op. cit.; Tano Ramos, Casas Viejas: crónica de una insidia (1933-1936), Barcelona, Tusquets, 2012.

42 Manuel AzAÑa, op. cit., p. 480. 
Viejas, sin guardar ningún tipo de cautela en sus manifestaciones. Por su parte, el ministro socialista Fernando de los Ríos decía al jefe del Ejecutivo que lo ocurrido en Casas Viejas era muy necesario, «dada la situación del campo andaluz y los antecedentes anarquistas en la provincia de Cádiz», mientras que el titular de Trabajo, Largo Caballero, aconsejaba que mientras durara la refriega, el rigor era «inexcusable» ${ }^{43}$. Sin embargo, diputados de la oposición como Eduardo Ortega y Gasset o Rafael Guerra del Río se hacían eco de otras informaciones que ya aparecían en la prensa de Madrid ${ }^{44}$.

No menos sorprendente era la actuación de la Justicia cuando acontecimientos como éste llegaban a los tribunales. En el proceso sobre los sucesos de Casas Viejas no se juzgaron los hechos relacionados con la quema de la casa de Seisdedos, con toda su familia dentro, sino, exclusivamente, el fusilamiento de las catorce personas: «diez de ellas esposadas, cuatro inermes y todas ellas impotentes ante un pelotón de hombres armados». Ningún guardia de asalto que participó en las ejecuciones fue procesado, mientras que el primer juicio contra el capitán Rojas, único encausado, quedó anulado. El segundo juicio se celebró en junio de 1935, y el jurado condenó a Rojas a noventa y ocho años de prisión, que por límite legal quedaron en veintiuno. Sin embargo, la defensa del acusado presentó un recurso ante el Tribunal Supremo, que calificó los asesinatos como simples homicidios y redujo la condena a catorce años, un año por cada uno de los ejecutados. Pero esta condena se redujo a tres años por la regla del triple de la pena más alta en el caso de varios delitos. En fin, que Rojas salió en libertad en marzo de $1936^{45}$.

Todos estos hechos facilitaban la reconducción de la propaganda anarquista sobre el resultado de las insurrecciones. El movimiento libertario volvía a poner en marcha lo que he denominado la «propaganda por la represión», para referirme a las actuaciones de los anarquistas a finales del siglo XIX. En aquel período, los resultados negativos cosechados con los atentados amparados en lo que denominaban la «propaganda por el hecho», les obligó a desviar la atención sobre la ilegal y cruenta represión ejercida por los gobiernos de la Restauración ${ }^{46}$. Ahora, en tiempos de la II República, la CNT veía cómo con los movimientos insurreccionales ya no sólo no conseguía alcanzar la revolución social, sino que la organización era desmantelada, sus militantes muertos o encarcelados, los sindicatos estaban cerrados mientras se prohibía la prensa libertaria. Pero es que los trabajadores que secundaban el movimiento tampoco obtenían resultados positivos, pues lejos de alcanzar cualquier mejora en sus condiciones de trabajo u aumento salarial, a la represión general tenían que añadir el despido de sus puestos de trabajo. Así que la CNT prefería en centrar sus protestas por la represión sufrida, en lugar de hacer autocrítica del camino emprendido. En los plenos se proponían propagandas que iban desde «atacar al Gobierno en las personas de los socialistas, quienes son los responsables de todo», hasta la edición de un folleto que cantara «el gesto heroico del camarada Seisdedos de Casas Viejas, como elemento de agitación que daría un resultado formidable a favor de la causa de los presos» ${ }^{47}$. Pero también se proponían nuevos movimientos y huelgas para protestar contra la represión.

43 Manuel Azaña, Diarios, 1932-1933. Los cuadernos robados, Barcelona, Crítica, 1997, p. 136.

44 Ramón J. Sender y Eduardo de Guzmán, que se personaron en el Casas Viejas tres días después de los sucesos, publicaron diferentes artículos en La Libertad y La Tierra desde el 19 de enero; Ramón J. SENDER, op. cit., p. XXXIV-XXXVI; Eduardo de GuZmán, op. cit., p. 41; Manuel AZAÑa, op. cit., p. 160.

45 Tano Ramos, op. cit., p. 341-342 y 350.

46 Ángel Herrerí, op. cit., p. 185-186.

47 IIHS, sig. CNT, 93 B. Extracto de las actas del Pleno Nacional de Regionales celebrado en Madrid, el 30 de enero de 1933. 
Como la huelga general de cuarenta y ocho horas convocada para el 9 y 10 de mayo de 1933, con un seguimiento escaso, motivado, precisamente, por la clausura de un buen número de sindicatos en toda España como consecuencia de las insurrecciones anteriores ${ }^{48}$.

En fin, que por mucho que desde las filas anarquistas se insistiera en el heroísmo de los compañeros «masacrados, diezmados, de nuevo sometidos, aunque no vencidos», y se dijera que esta era la «pauta a seguir» ${ }^{49}$, lo cierto era que la CNT estaba al borde del colapso; $y$, sin embargo, a pesar de que la organización reconocía la necesidad de reorganizarse, se insistía en el maximalismo revolucionario. Volvía a plantearse la restricción de la huelga con fines concretos «en holocausto al movimiento revolucionario», lo que suponía prepararse «para la revolución dejando de lado los movimientos serviles para convertirlos en actos decisivos» ${ }^{50}$. Era una huida hacia adelante de consecuencias previsibles.

\section{La insurrección de diciembre de 1933}

En repetidas ocasiones se ha señalado la incongruencia que significaba la advertencia de la CNT de lanzarse a un movimiento insurreccional si las derechas ganaban las elecciones de finales de 1933, sobre todo teniendo en cuenta que había defendido de forma activa la abstención. También se ha planteado que el objetivo de la CNT era provocar una baja participación que deslegitimara el sistema y justificara el intento revolucionario. Pero si se atiende a las reuniones cenetistas, que se celebraron desde la primera mitad de 1933, se percibe el sentimiento de intranquilidad que para el movimiento suponía la posibilidad de la instauración de un régimen fascista en España. Un régimen que «se ensañaría contra los militantes de la Confederación de una forma cruel», y cuya entronización supondría perder las «posibilidades revolucionarias para un sin fin de años más» ${ }^{51}$.

Era evidente, después del fracaso de los dos intentos anteriores, que la CNT no se bastaba por sí sola para alcanzar la revolución, y necesitaba la colaboración de otras fuerzas de la izquierda. La estrategia confederal pasaba, en primer lugar, por desalojar del Poder a los socialistas para, a continuación, empujarles al campo insurreccional. La necesidad de la acción conjunta venía determinada por el ejemplo del ascenso del fascismo en países como Italia y Alemania, o de regímenes autoritarios, como en el caso de Austria. En el Pleno Nacional de Regionales, que la CNT celebró en febrero de 1934, el delegado de la regional de Centro indicaba que, tras la importante abstención registrada en los comicios, la mayoría de la organización pensaba, con «criterio irrefutable», que «como consecuencia de haber escalado el Poder las derechas, se sumarían al movimiento revolucionario todos cuantos hombres de izquierdas desearan un mañana mejor $\rangle^{52}$. Pero los cenetistas volvían a errar en el análisis de la realidad. Porque una cosa era no ir a votar en las elecciones y otra muy diferente lanzarse a la insurrección, por mucho que se señalara el ejemplo de la fuerte represión y pérdida de la libertad que sucedía en otros países de Europa.

48 IIHS, sig. CNT, 93 B. Extracto de las actas del Pleno Nacional de Regionales celebrado en Madrid, el 12 de junio de 1933.

49 Federica MonTSENY, «Los pueblos que proclaman el Comunismo libertario», El Luchador; en Antonio Elorza, op. cit., p. 456.

50 IIHS, sig. CNT, 93 B. Extracto de las actas del Pleno Nacional de Regionales celebrado en Madrid, el 12 de junio de 1933.

51 IIHS, sig. CNT, 93 B. Circular del Comité Regional de Cataluña, 25 de marzo de 1933.

52 IIHS, sig. CNT, 93 B. Actas del Pleno Nacional de Regionales celebrado en Barcelona, en febrero de 1934. 
Así que la CNT volvió a protagonizar en solitario el intento revolucionario de diciembre de 1933. Un intento que ha sido destacado como el de mayor organización y envergadura de los realizados en tiempos republicanos. Sin embargo, la lectura de los documentos emanados por la propia organización ponen, cuando menos, en duda que la Confederación contara con más medios y presencia que en acciones anteriores $\mathrm{y}$, en consecuencia, con más posibilidades de éxito. En primer lugar, porque las intervenciones de los delegados en las reuniones confederales donde se decidió la insurrección no se correspondían con los acuerdos de las regionales que representaban. Esta situación llevó a la Regional de Aragón, Rioja y Navarra, que fue la más combativa, a señalar:

Que siempre, y en todos nuestros comicios, tengamos por norma la expresión sincera de nuestra labor informativa y deductiva, para que nunca fuera la verborrea más o menos cálida y el temperamento frío o apasionado de los delegados, quienes influyan o cambien el fondo del acuerdo con el que son enviados; que las regionales avalen o envíen sus delegados con los acuerdos tomados, en síntesis, sin perjuicio de que estos, y aquí caben todos los recursos teóricos, den la forma que puedan producir los mejores efectos, pero siempre sin alterar las líneas esenciales y el fondo de los acuerdos ${ }^{53}$.

Así que, aunque los delegados transmitieran la predisposición de sus regionales a la acción, lo cierto era que la mayoría no estaban preparadas, como reconocieron las de Andalucía y Extremadura, Norte, Galicia, Asturias y Centro. Otras, aún sin admitirlo abiertamente, tampoco lo estaban. Era el caso de la emblemática regional catalana. Aquí las esperanzas estaban depositadas en Barcelona, donde los militantes más significados sustentaban el criterio «de que el momento no era oportuno», aunque, no obstante, si el movimiento estallaba, «ellos cumplirían con su deber». El secretariado del Comité Regional decidió editar una hoja clandestina, «que no llegó a ver la luz pública», por el retraso en su edición y por «la lamentable situación económica de este Secretariado». De todas formas, se lanzaron unos manifiestos en la capital, y se decidió que el día 8 de diciembre arrancara la insurrección. El día 9, «en muy pocas localidades de Cataluña, el movimiento había tenido repercusión», con excepción del Bajo Llobregat, especialmente en Hospitalet. Mientras que en Barcelona, hubo «unos actos de sabotaje en algún punto de poca importancia». Un pleno de sindicatos acordó impulsar el movimiento en los días siguientes, pero el 11 y 12 pasaron «sin que nada anormal ocurra en Barcelona, salvo unas escaramuzas ocurridas en las barriadas de Sans y Coll-Blanch». Un nuevo pleno, celebrado el día 12, acordó volver al trabajo «ante la imposibilidad de hacer nada práctico». Tras lo acontecido, el Comité Regional presentó su dimisión y el Comité de Defensa Local aseguraba que «siempre mantuvieron que Barcelona no estaba en condiciones de acometer o de iniciar el ataque por carecer de medios combativos». El informe terminaba concluyendo que en el resto de Cataluña no se hizo prácticamente nada ${ }^{54}$.

El único lugar dónde los acontecimientos alcanzaron proporciones de insurrección fue en la regional de Aragón, Rioja y Navarra. Los propios militantes reconocieron «ciertamente, que a nuestra Regional se la ha dejado sola». Las acciones no se circunscribieron, exclusivamente, a las capitales, sino que se extendieron por los pueblos de alrededor: Mas de las Matas, Alcoriza, Alcañiz... La ciudad de Zaragoza fue testigo de una auténtica batalla

53 IIHS, sig. CNT, 93 B. Actas del Pleno Nacional de Regionales celebrado en Barcelona, en febrero de 1934.

54 Ibidem. 
campal en sus calles. El ejército utilizó todos los medios a su alcance, desde ametralladoras a tanques, para reducir a los insurrectos parapetados tras barricadas.

La insurrección se cobró la vida de ciento y veinticinco personas y hubo ciento ochenta y seis heridos; entre los insurrectos sesenta y cinco muertos y treinta y ocho heridos; entre los ciudadanos que no tenían que ver con el movimiento hubo cuarenta y cuatro muertos y ochenta y cinco heridos. Las fuerzas del orden tuvieron dieciséis muertos y setenta y tres heridos ${ }^{55}$. Además, hubo cientos de detenidos, y no faltaron denuncias de torturas, incluidos fusilamientos simulados. Otra cuestión a señalar es el salto cualitativo en la represión ejercida por los revolucionarios, que fue superior a la de anteriores movimientos. En algunos pueblos, se colgaron bandos conminando a la población a someterse al nuevo régimen para salvar su vida. En el mismo sentido, hubo detención de caciques y grandes propietarios, se registraron quemas de iglesias y la muerte de algún religioso ${ }^{56}$.

De todas formas, los cenetistas no contaron, como era habitual, con el dinero ni las armas suficientes para «combatir al bien pertrechado enemigo». Aunque, también como solía suceder, «hubo heroísmo que es lo que viene derrochando a raudales muchos militantes de la $\mathrm{CNT} \gg{ }^{57}$. Heroísmo, pero también falta de planificación y análisis real del momento, que había llevado a la organización al borde del colapso, con:

organizaciones enteras de la CNT completamente hundidas; Locales y Comarcales destrozadas con la mayoría de militantes presos y sometidos al rigor de los tribunales de urgencia; trenes repletos de militantes que partían hacia el presidio de Chinchilla...; clausurados los sindicatos gubernativamente y con una orden judicial del tribunal de urgencia de Zaragoza, de disolución de la CNT y procesamiento de todos los Comités de la misma. Así Regionales como Comarcales y Locales; nuestros periódicos suspendidos y prohibidos los actos públicos. Éramos el Comité Nacional de una organización que por cien motivos distintos, estaba condenada a muerte... ${ }^{58}$.

En estas circunstancias, regionales como Centro y Asturias comenzaron a promover una nueva corriente partidaria de un acuerdo con la UGT. Su representación más importante tuvo lugar en los meses siguientes con la famosa revolución de octubre.

\section{Conclusiones}

Los anarquistas estaban convencidos de que lo acontecido el 14 de abril de 1931 había sido una revolución, pero que la falta de acción de los militantes cenetistas en esos días decisivos había facilitado a republicanos y socialistas el control de los resortes del Poder y el desliz del movimiento hacia la implantación de una república burguesa. De todas formas, para los anarquistas, el momento revolucionario no había pasado, todavía era posible un cambio de rumbo que permitiera la implantación de una sociedad libertaria. Para conseguir este objetivo necesitaban, por un lado, hacerse con el control de los puestos directivos de la CNT y, por otro lado, promover acciones que crearan las circunstancias adecuadas para movilizar a la ciudadanía y desencadenar una auténtica revolución social.

55 Roberto VILLA, op. cit., «La CNT contra la república: La insurrección revolucionaria de diciembre de 1933», Historia y Politica ${ }^{\circ} 5$, enero-junio 2011, p. 177-205.

56 IIHS, sig. CNT, 93 B. Actas del Pleno Nacional de Regionales celebrado en Barcelona, en febrero de 1934; Antonio Elorza, op. cit., p. 462-463.

57 IIHS, sig. CNT, 93 B. Actas del Pleno Nacional de Regionales celebrado en Barcelona, en febrero de 1934.

58 IIHS, sig. CNT, 93 B. Informe del Comité Nacional de la CNT del 20 de enero de 1934, firmado en Barcelona el 26 de febrero de 1934. 
Aunque la historiografía siempre ha señalado que fueron tres las insurrecciones protagonizadas por la CNT en tiempos republicanos - en enero de 1932 y enero y diciembre del año siguiente-, hay que añadir un matiz importante: la primera de ellas no puede considerarse como una insurrección promovida y dirigida por la organización confederal. El levantamiento en el Alto Llobregat fue un movimiento huelguístico circunscrito a una comarca catalana que derivó en insurrección en algunos pueblos de la zona; pero que no contó con la implicación -ni tan siquiera con el conocimiento- de la dirección de la CNT a nivel regional ni nacional. Sin embargo, este movimiento tuvo una importancia destacada para el devenir del sindicato confederal; en primer lugar, por la repercusión que tuvo en la lucha interna de la organización, con la sustitución de los anarcosindicalistas por los «faístas» al frente del sindicato confederal; y, en segundo lugar, porque lo sucedido en la comarca catalana se quiso interpretar como el camino a seguir en cuyo final se vislumbraba, aunque fuera remotamente, la futura sociedad libertaria.

La actuación del gobierno republicano, tanto en materia de legislación laboral como de orden público, facilitó la labor de los más radicales en la CNT. A finales de 1932, los «faístas» controlaban todos los puestos claves de la organización sindical; mientras que la República era denostada, con la consiguiente decepción de un buen número de obreros y campesinos. En esta aventura, la CNT pasó de actuaciones que, en los años anteriores, habían tenido un marcado carácter sindical, con huelgas que permitieron mejorar las condiciones de vida de los trabajadores, a movimientos insurreccionales de carácter nacional, ahora sí con la organización y dirección confederal, que pretendían la consecución de la revolución social.

Pero estas insurrecciones no consiguieron su objetivo. No hubo posibilidad real de que estos movimientos terminaran con el triunfo de la revolución. Les faltaba organización y medios, así como un auténtico apoyo popular y las armas necesarias, o el apoyo de aquellos que las tenían, los militares. Sin embargo, las insurrecciones consiguieron desestabilizar a la República y desgastar, de forma especial, al gobierno republicano-socialista. Pero nunca supusieron una amenaza real para el sistema, nunca podían triunfar mientras las fuerzas que defendian el orden permanecieran unidas. Solamente cuando una parte del Ejército se levantó contra la República y hubo desunión en su seno, como sucedió en la rebelión militar de julio de 1936, se abrió, aunque sea paradójico, el camino de la revolución. 